\title{
Management of Tooth and Observation of External Root Surface with Extrusion of Calcium Hydroxide-Containing Paste
}

\section{Yoshiko Murakami Masuda ${ }^{1 *}$, Shigenori Suzuki ${ }^{1}$, Yukiko Matsuda ${ }^{2}$, Yuichi Kimura ${ }^{3}$ and Takashi Miyazaki ${ }^{4}$}

${ }^{1}$ Department of Conservative Dentistry, Division of Endodontology, Showa University School of Dentistry, 2-1-1 Kitasenzoku, Ohta-ku, Tokyo 145-8515, Japan ${ }^{2}$ Department of Oral Diagnostic Sciences, Division of Radiology, Showa University School of Dentistry, 2-1-1 Kitasenzoku, Ohta-ku, Tokyo 145-8515, Japan ${ }^{3}$ Division of Endodontics, Department of Conservative Dentistry, Ohu University School of Dentistry, 31-1, Misumido, Tomita-machi, Koriyama, Fukushima 963-8611, Japan

${ }^{4}$ Department of Conservative Dentistry, Division of Oral Biomaterials and Technology, Showa University School of Dentistry, 2-1-1 Kitasenzoku, Ohta-ku, Tokyo 145-8515, Japan

\begin{abstract}
Introduction: Extrusion of the root canal filling materials is often absorbed and heals, which produces no irreversible changes. However, sometimes it causes the persisting pain and apical radiolucent. This case shows that extrusion of calcium hydroxide $\left[\mathrm{Ca}(\mathrm{OH})_{2}\right]$ intracanal medicament caused the persistent percussion pain.

Methods: This case report describes the patient with extrusion of $\mathrm{Ca}(\mathrm{OH})_{2}$ into the periapical tissue in the mandibular right second premolar. A 48-year-old female presented with persistent occlusal pain. Radiographs revealed a radiolucent lesion in the periapical region of mandibular second premolar. The cone-beam computed tomography scan revealed the non-radiolucency root canal materials around the root apex and periapical radiolucency was present along with considerable external root resorption. After preparation, root canal was filled with gutta-percha cones and root canal sealer, and intentional replantation with apicoectomy was performed. The resected portion of root apex was observed by stereomicroscopy and scanning electron microscopy (SEM).

Results: The root surface contacted with $\mathrm{Ca}(\mathrm{OH})_{2}$ paste was observed by stereomicroscopy. SEM observation revealed that the area of the apical foramen was covered with the complex of the extended materials and resorption of apex was observed. At the 1-month recall appointment, the patient presented asymptomatically without tooth mobility. Five months after the surgery, radiograph showed new bone formation around periapical region. The patient had no clinical symptoms of pain.

Conclusions: The treatment had been successful, achieving adequate repair with 9 months of follow-up. Appropriate size of the apical foramen was essential for success of the root canal treatment. Extrusion of $\mathrm{Ca}(\mathrm{OH})_{2} \mathrm{paste}$ caused persistent occlusal pain and the apical foramen coverage by the materials.
\end{abstract}

Keywords: $\mathrm{Ca}(\mathrm{OH})_{2}$ paste; Extrusion of the root canal filling materials; SEM observation

\section{Introduction}

Extrusion of the root canal filling materials sometimes causes permanent complication. Slight to moderate overextensions with insert conventional endodontic sealers, such as gutta-percha with Grossman's sealant, often repair themselves and produce no irreversible changes with direct contact into the sinus [1]. According to the analysis of the cause of failure in nonsurgical endodontic treatment, overfilling was responsible for small portion of failure, within 3\% [2]. However, Nair reported that foreign materials trapped in periapical tissue during and after endodontic treatment can perpetuate apical periodontitis persisting after root canal treatment. Foreign materials can reach the periapex, induce a foreign body reaction that appears radiolucent and remain asymptomatic for several years [3]. Foreign materials include amalgam, endodontic sealants and calcium salts derived from periapically extruded $\mathrm{Ca}(\mathrm{OH})_{2}$ [4].

This case shows that extrusion of calcium hydroxide $\left[\mathrm{Ca}(\mathrm{OH})_{2}\right]$ intracanal medicament caused the persistent percussion pain.

\section{Case Report}

A 48-year-old female was referred to the Division of Endodontics, Showa University Dental Hospital. The patient had the chief compliant of occlusal pain in the right mandibular second premolar. Initially the patient received the retention procedures for stabilizing tooth position after orthodontic treatment. Before 3 months, she had received the endodontic treatment for its spontaneous pain in the right mandibular second premolar in another clinic. After several endodontic treatments, the continuous occlusal pain had remained. The private dentist explained that the tooth should be extraction. The patient urged to tooth conservation and referred to our Dental Hospital.

Clinical examination showed that no pain on vertical percussion. The tooth was periodontally healthy and no mobility was noted. The patient medical history was noncontributory. An intraoral periapical radiograph revealed a mandibular second premolar with a prepared access cavity and a root with radiolucent legion was present in the periapical area (Figure 1A). The large amount of root canal materials was spilled into the periapical area. The root canal material was calcium hydroxide-containing paste (Calcipex II', Nippon Shika Yakuhin Co., Ltd, Shimonoseki, Japan). At first, the root canal treatment was performed. The root canal length was measured by root ZX (Morita, Kyoto, Japan) and the size of root apex was already prepared with \#90 K-file.

*Corresponding author: Yoshiko Murakami Masuda, DDS, PhD, 1Department of Conservative Dentistry, Division of Endodontology, Showa University School of Dentistry, 2-1-1 Kitasenzoku, Ohta-ku, Tokyo 145-8515, Japan, Tel: +81-3-37871229; E-mail: yoshik@dent.showa-u.ac.jp

Received March 28, 2015; Accepted April 22, 2015; Published April 25, 2015

Citation: Masuda YM, Suzuki S, Matsuda Y, Kimura Y, Miyazaki T (2015) Management of Tooth and Observation of External Root Surface with Extrusion of Calcium Hydroxide-Containing Paste. Dentistry 5: 301. doi:10.4172/21611122.1000301

Copyright: @ 2015 Masuda YM, et al. This is an open-access article distributed under the terms of the Creative Commons Attribution License, which permits unrestricted use, distribution, and reproduction in any medium, provided the original author and source are credited. 

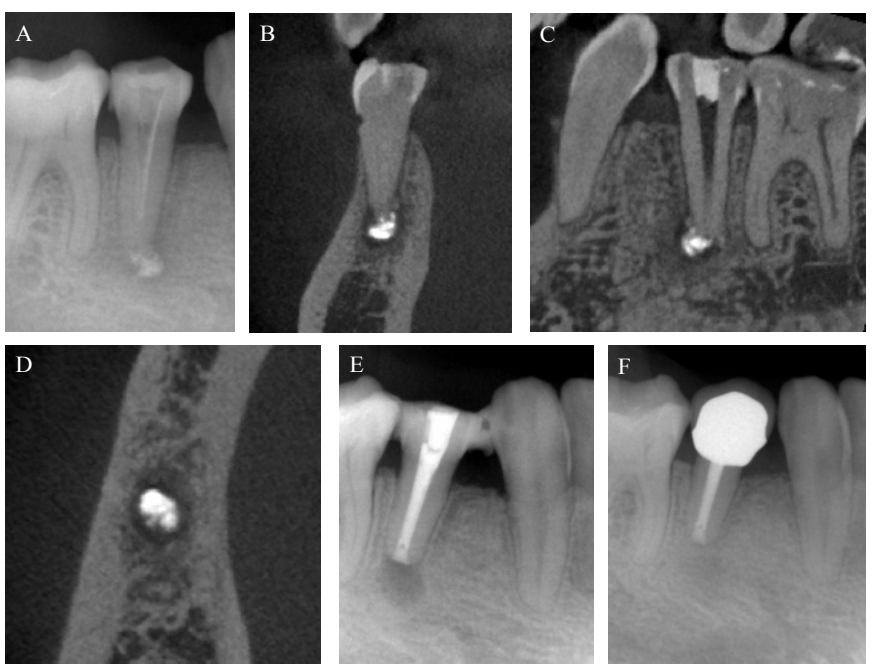

Figure 1: (A) Preoperative radiograph of the right mandibular second premolar, (B-D) CBCT images, (E) Post-operative radiograph, (F) Radiograph at 5-month- recall.

At next appointment, a cone-beam computed tomography (CBCT; Hitachi, Tokyo, Japan) was performed with exposure parameters of 60 $\mathrm{kV}, 8 \mathrm{~mA}, 0.08$ seconds was taken of the area (Figures $1 \mathrm{~B}, \mathrm{C}$ and $\mathrm{D}$ ). The CBCT scan revealed the presence of periapical radiolucency and non-radiolucency root canal materials around the root apex. Periapical radiolucency was present, measuring $7 \times 8 \mathrm{~mm}$, along with considerable external root resorption affecting the apical region, particularly on its mesial aspect. It seems to present the external root resorption. After a total of 3 instrumentation sessions, it was decided to perform periradicular surgery of intentional replantation with apicoectomy.

After rubber dam isolation, the intracanal medication was removed, and the canal was filled with gutta-percha cones and root canal sealer (Canals N; Showa Yakuhin Kako Co. Ltd, Tokyo, Japan) by using the lateral compaction technique.

Then, the tooth was anesthetized with $1.8 \mathrm{ml}, 20 \mathrm{mg}$ lidocaine containing $0.045 \mathrm{mg}$ adrenaline bitartrate (ORA ${ }^{*}$ Inj. Dental Cartridge; Showa Yakuhin Kako Co. Ltd, Tokyo, Japan) and gently extracted by dental extracting forceps. The root surface was kept moist by wrapping the root with gauze soaked in a sterilized saline.

Under the microscope, root of approximately apical $4 \mathrm{~mm}$ of the tooth was resected. After root-end cavity was prepared ultrasonically, SuperEBA (Bosworth Company, Skokie, IL, USA) was placed and condensed into root-end cavity preparation. The tooth was replanted and the splint was applied (Figure 1E).

Stereomicroscopic observation showed that the root surface around apex foramen was covered with calcium hydroxide-containing paste (Figure 2). SEM observation revealed that the surface of the root apex was covered by the extended materials and root resorption was observed (Figures $3 \mathrm{~A}$ and $\mathrm{B}$ ).

At the 1-month recall appointment, the splint was removed. The patient presented asymptomatically. The mobility of the tooth was normal. The patient was subsequently followed up at regular intervals. Five months after the surgery, radiograph showed new bone formation around periapical region (Figure 1F). The patient had no clinical symptoms of pain.

\section{Discussion}

Calcium hydroxide has been used in endodontic therapy since 1920 when Hermann described his study [5]. The clinical effectiveness of calcium hydroxide in infected canals has been reported [6,7]. Calcium hydroxide has a high $\mathrm{pH}$, and its dental use relates chiefly to its ability to stimulate mineralization, and also to its antibacterial properties [8]. A range of products has been formulated with different therapeutic actions, the effects of which are partially dependent upon the tissue to which they are applied. Nerwich reported $\mathrm{pH}$ changes in dentin after the root canal with calcium hydroxide [9]. After medication, the hydroxyl ions diffuse from the root canal into the surrounding, inner dentin within hours in the cervical part of the root and within days in the apical part. The hydroxyl ions have the anti-bacterial effect. Hasselgren reported that treatment with calcium hydroxide has also been shown to dissolve necrotic tissue and enhance the tissue dissolving effect of sodium hypochlorite $(\mathrm{NaOCl})$ solution [10]. Many investigators reported the biocompatibility of calcium hydroxide. Histological examination was carried out to assess the biocompatibility of Calcipex II and Calcipex Plane II, new calcium hydroxide-containing pastes and these calcium hydroxide-containing pastes were revealed biocompatible [11-14]. Extended calcium hydroxide over the apical foramen contacted the periapical tissues. Rusmussen reported the calcium hydroxide direct

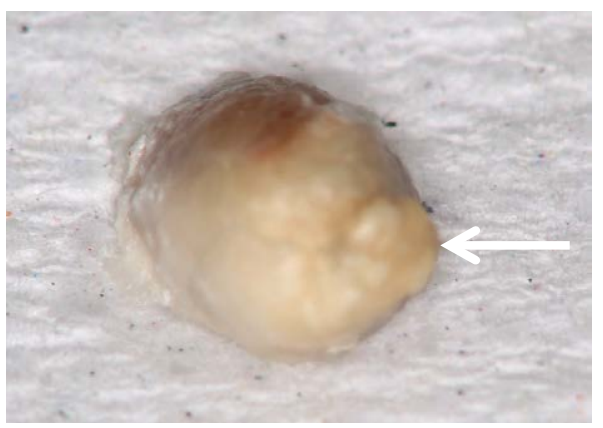

Figure 2: Stereomicroscopic observation of resected root apex (arrow: calcium hydroxide-containing paste).
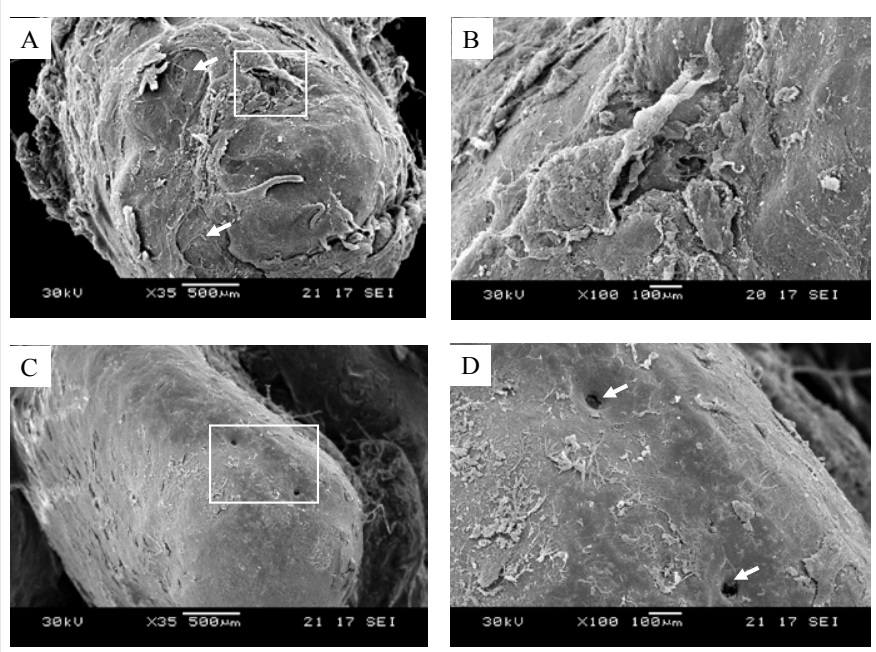

Figure 3: SEM observation of resected root apex, (A) The surface of the apex, (B) a higher magnification of the image shown in A, (C) The normal surface of the root apex without apical periodontitis, (D) a higher magnification of the image shown in C (arrows: apical foramen). 
contact with the connective tissue in vivo and it showed the mineralized tissues [15]. Rotstein in the case report, showed the extended calcium hydroxide was effective [14]. Holland concluded that a larger size of the apical foramen made a better contact between the material and the periapical tissue [16]. On the other side, Smith reported that extended calcium hydroxide material was not completely resorbed. If left for a long period, it induced a concentric pattern of calcification around itself similar to dystrophic calcification [11]. Therefore, it was recommended that whenever possible the material should be confined within the limits of the root canal $[11,17,18]$. This case suggested that the materials should be confined within the root canal. Therefore, it was considered that the extended calcium hydroxide material might cause the continuous occlusal pain for 10 months. However, other causes of persistent pain are known in apical periodontitis. The apical foramen of the case was broken, which itself can be one of persistent pain, because the excess enlargement of the apical foramen can lead the micro-fracture of the root apex, as well as persistent inflammation of periapical root tissue ( Figures 2 and 3).

In this case, the patient was referred. It was not clear when the occlusal pain occurred, before applying this paste or afterward. It was considered that the patient might already sense the occlusal pain before calcium medication unless it was used in initial preparation after pulpectomy for the extra-enlargement of root canal by the former doctor.

Physical (overfilling) and chemical (irrigants, intracanal medication, root canal filling materials) insults to the periapical tissues, can also cause apical periodontitis, depending on the severity of injury and cytotoxicity of the chemicals [19]. Foreign bodies, only themselves, such as root canal filling materials, have been shown to cause persistent periapical inflammation $[20,21]$. It might be considered that the calcium or other components irritated the nerve within periradicular tissue. It is possible that the foreign bodies served as carriers for the microorganism. In addition, foreign bodies have the odd property of favoring infection because they cause granulocytes to develop phagocytic defect, loss of ammunition [22]. It was considerable the excess enlargement of the apical foramen might trigger the cracks at the apical portion and the cracks caused the continuous occlusal pain.

In this case, the external absorption was seen. The resorption of root cementum and/or dentin in apical periodontitis lesions is less well understood than resorption of bone [19]. The cells responsible for dental hard-tissue resorption are called odontoclasts [23]. Its ultrastructure and gene expression are similar to those of the osteoclasts. Nevertheless, little is known about what causes odontoclast differentiation and activation to resorb dentin and cementum. Several cytokines and growth factors, such as granulocyte/macrophage RANKL, IL-1, IL-6, TNF and prostaglandins, have been shown to mediate osteoclast differentiation [24]. It might be considerable they attended the odontoclast differentiation.

\section{Conclusion}

According to the anatomical investigation, approximately $75 \%$ of teeth have canal irregularities (e.g., accessory or lateral canals) in the apical $3 \mathrm{~mm}$ of the tooth $[24,25]$. Adorno reported that in Japanese anterior maxillary teeth, a high percentage of accessory canals can be found in apical $3 \mathrm{~mm}$ of the root [26]. An apical resection of approximately $3 \mathrm{~mm}$ should include most accessory and lateral canals and thus eliminate most residual microorganisms and irritants [19]. This time approximately apical $4 \mathrm{~mm}$ of the tooth was resected. The area of external root resorption was removed in this case.
The root canal was already enlarged up to a size \#90 with a K-file (Kavo Dental Systems Japan Co., Ltd.) by referred dentist. The mean canal width at cementodentinal junction in mandibular premolars was $0.32 \mathrm{~mm}$ [27]. In this case, prepared canal width at cementodentinal junction was $0.9 \mathrm{~mm}$. The apical constriction was destroyed by root canal preparation. Too large apical foramen caused the extrusion of Calcipex into the periapical tissues and cracks. Appropriate size of the apical foramen was essential for success of the root canal treatment. Extruded $\mathrm{Ca}(\mathrm{OH})_{2}$ paste might cause the persistent occlusal pain and the apical foramen coverage by the materials.

\section{Acknowledgments}

The authors deny any conflicts of interest related to this study.

\section{References}

1. Hargreaves KM, Cohen S, Berman LH (2011) Pathways of the pulp. Elsevier, Chapter 11, Mosby Co. St. Louis, Missouri, USA, p 429.

2. Song M, Kim HC, Lee W, Kim E (2011) Analysis of the cause of failure in nonsurgical endodontic treatment by microscopic inspection during endodontic microsurgery. J Endod 37: 1516-1519.

3. Nair PN, Sjogren U, Krey G, Sundqvist G (1990) Therapy-resistant foreign body giant cell granuloma at the periapex of a root-filled human tooth. J Endod 16 : 589-595.

4. Nair PN (2006) On the causes of persistent apical periodontitis: a review. Int Endod J 39: 249-281.

5. Hermann BW (1920) Calcium hydroxide as a means to treat and fillings of tooth root canals. Med. Diss. V, Wurzburg.

6. Bystrom A, Claesson R, Sundqvist G (1985) The antibacterial effect of camphorated paramonochlorophenol, camphorated phenol and calcium hydroxide in the treatment of infected root canals. Endod Dent Traumatol 1: 170-175.

7. Cvek M, Hollender L, Nord CE (1976) Treatment of non-vital permanent incisors with calcium hydroxide. VI. A clinical, microbiological and radiological evaluation of treatment in one sitting of teeth with mature or immature root Odontol Revy 27: 93-108.

8. Foreman PC, Barnes IE (1990) Review of calcium hydroxide. Int Endod J 23 283-297.

9. Nerwich A, Figdor D, Messer $\mathrm{HH}$ (1993) $\mathrm{pH}$ changes in root dentin over a 4-week period following root canal dressing with calcium hydroxide. J Endod 19: 302-306.

10. Hasselgren G, Olsson B, Cvek M (1988) Effects of calcium hydroxide and sodium hypochlorite on the dissolution of necrotic porcine muscle tissue. $J$ Endod 14: 125-127.

11. Smith JW, Leeb IJ, Torney DL (1984) A comparison of calcium hydroxide and barium hydroxide as agents for inducing apical closure. J Endod 10: 64-70.

12. Pitt Ford TR, Rowe AH (1989) A new root canal sealer based on calcium hydroxide. J Endod 15: 286-289.

13. Sonat B, Dalat D, Gunhan O (1990) Periapical tissue reaction to root fillings with Sealapex. Int Endod J 23: 46-52.

14. Kimura A, Haraguchi Y, Nakamuta H, Yoshimine Y, Akamine A (2005) Histological examination of the biocompatibility of Calcipex II and Calcipex Plane II. J Jpn Endod Assoc 26:50-6

15. Soares JA, Silveira FF, Nunes E (2007) Apical surgery with calcium hydroxide capping of the exposed dentine: a case report. J Oral Sci 49: 79-83.

16. Holland R, Nery MJ, de Mello W, de Souza V, Bernabé PF, et al. (1979) Root canal treatment with calcium hydroxide. II. Effect of instrumentation beyond the apices. Oral Surg Oral Med Oral Pathol 47: 93-96.

17. Vernieks AA, Messer LB (1978) Calcium hydroxide induced healing of periapical lesions: a study of 78 non-vital teeth. J Br Endod Soc 11: 61-69.

18. Holland R, Nery MJ, de Mello W, de Souza V, Bernabé PF, et al. (1979) Root canal treatment with calcium hydroxide. I. Effect of overfilling and refilling. Oral Surg Oral Med Oral Pathol 47: 87-92. 
Citation: Masuda YM, Suzuki S, Matsuda Y, Kimura Y, Miyazaki T (2015) Management of Tooth and Observation of External Root Surface with Extrusion of Calcium Hydroxide-Containing Paste. Dentistry 5: 301. doi:10.4172/2161-1122.1000301

19. Hargreaves KM, Cohen S, Berman LH (2011) Pathways of the pulp (10thedtn). Elsevier, Chapter 14, p 531: Mosby Co. St. Louis, Missouri, USA.

20. Pascon EA, Leonardo MR, Safavi K, Langeland K (1991) Tissue reaction to endodontic materials: methods, criteria, assessment, and observations. Oral Surg Oral Med Oral Pathol 72: 222-237.

21. Yusuf $H$ (1982) The significance of the presence of foreign material periapically as a cause of failure of root treatment. Oral Surg Oral Med Oral Pathol 54: 566-574.

22. Zimmerli W, Lew PD, Waldvogel FA (1984) Pathogenesis of foreign body infection. Evidence for a local granulocyte defect. J Clin Invest 73: 1191-1200.

23. Sahara N, Toyoki A, Ashizawa Y, Deguchi T, Suzuki K (1996) Cytodifferentiation of the odontoclast prior to the shedding of human deciduous teeth: an ultrastructural and cytochemical study. Anat Rec 244: 33-49.
24. De Deus QD (1975) Frequency, location, and direction of the lateral, secondary, and accessory canals. J Endod 1: 361-366.

25. Seltzer S, Soltanoff W, Bender IB, Ziontz M (1966) Biologic aspects of endodontics: I. Histologic observations of the anatomy and morphology of root apices and surrounding structures. Oral Surg Oral Med Oral Pathol 22:375-85.

26. Adorno CG, Yoshioka T, Suda H (2010) Incidence of accessory canals in Japanese anterior maxillary teeth following root canal filling ex vivo. Int Endod J 43: 370-376.

27. Hassanien EE, Hashem A, Chalfin H (2008) Histomorphometric study of the root apex of mandibular premolar teeth: an attempt to correlate working length measured with electronic and radiograph methods to various anatomic positions in the apical portion of the canal. J Endod 34:408-12. 